\title{
Prognostic Significance of CT Scan in Malignant Glioma
}

\author{
Shogo Yamada, Yoshiniro Takai, Kenji Nemoto, \\ Yoshiniro Ogawa, Yoshinisa Kakuto, Akihiko Hoshi \\ and Kiуohiкo Sakamoto \\ Department of Radiology, Tohoku University School of \\ Medicine, Sendai 980
}

\begin{abstract}
Yamada, S., TakaI, Y., Nemoto, K., Ogawa, Y., Kakuto, Y., Hoshi, A. and Saкамото, K. Prognostic Significance of CT Scan in Malignant Glioma. Tohoku J. Exp. Med., 1993, $170(1), 35-43$ In 91 malignant gliomas treated with radiation therapy, CT scan which was taken before treatment was reviewed to examine the significance as a prognostic indicator. The irradiation methods and the surgical resectability did not affect the survival. Similarly, the tumor location and the grade of the low density area (LDA) surrounding the contrast enhanced area (CEA) had no significance on the prognosis. As a result of the multi-variate analysis, the histopathologic diagnosis, the CEA size and the CEA pattern were significantly important prognostic factors. Astrocytoma grade III, a CEA diameter of under $4 \mathrm{~cm}$ and a homogeneous CEA were favorable indicators of the malignant gliomas. Tumors with a heterogeneous or a ring-like CEA in the diameter of more than $4 \mathrm{~cm}$ have the worse prognosis and should be treated extensively by radiation therapy. —— brain neoplasm; malignant glioma; CT; therapeutic radiology; prognostic factor
\end{abstract}

Malignant glioma is histopathologically classified into two groups by the existence of coagulation necrosis in the tumor: anaplastic astrocytoma and glioblastoma multiforme (Zülch 1979). Glioblastoma possesses coagulation necrosis and its prognosis is worse than astrocytoma grade III (Nelson et al. 1983; Deutsch et al. 1989; Shapiro et al. 1989; Sandeman et al. 1990). However, the specimens by stereotactic biopsy are not enough to judge the integral nature of a tumor, and in some cases we must start radiation therapy without any histopathological proof. We examined the correlation between computed tomography (CT) scan taken before treatment and the prognosis of a malignant glioma to know whether we can predict prognosis through the CT scan.

\section{Materials and Methods}

Ninety one histopathologically diagnosed malignant gliomas treated at the Department

Received November 11, 1992; revision accepted for publication April 7, 1993.

Address for reprint: Shogo Yamada, M.D. Department of Radiology, Tohoku University School of Medicine, 1-1 Seiryomachi, Aobaku, Sendai 980, Japan. 
of Radiology, Tohoku University School of Medicine during the period of 1980 through 1990 were analyzed. There were 53 males and 38 females, and average age was 50.9 years (range, 3-76 years). Fifty cases were diagnosed as astrocytoma grade III and 41 as glioblastoma.

We tried various radiation methods. Forty four patients were treated with conventionally fractionated irradiation combined once a week with chemotherapy using 1-(4-amino-2methyl-5-pyrimidinyl) methyl-3-(2-chloroethyl)-3-nitrosourea hydrochloride (ACNU, $1 \mathrm{mg}$ / $\mathrm{kg}$ ). They received a total dose of $60 \mathrm{~Gy}$. Thirty one patients underwent uneven fractionated irradiation: a radiation dose of $5 \mathrm{~Gy}$ combined with ACNU ( $1 \mathrm{mg} / \mathrm{kg}$ ) on Monday followed by 1 Gy per fraction from Tuesday through Friday. A total dose of 54 Gy was delivered by this method. Eight patients received a low dose rate telecobalt therapy (LDRT) as a boost: a conventional radiation dose of 60 Gy followed by 14 Gy of the LDRT: $1 \mathrm{~Gy} / \mathrm{hr}, 7 \mathrm{~Gy} /$ day. Eight patients were treated with $15 \mathrm{~Gy}$ of intraoperative

TABLE 1. Histopathologic diagnosis and CT patterns

\begin{tabular}{|c|c|c|c|}
\hline & Anaplastic astrocytoma & Glioblastoma & Total \\
\hline \multicolumn{4}{|l|}{ Tumor location } \\
\hline Right side & 28 & 16 & 44 \\
\hline Left side & 14 & 22 & 36 \\
\hline Both side & 8 & 3 & 11 \\
\hline Frontal & 16 & 14 & 30 \\
\hline Temporal & 15 & 14 & 29 \\
\hline Parietal & 9 & 5 & 14 \\
\hline Occipital & 4 & 7 & 11 \\
\hline Others & 6 & 1 & 7 \\
\hline \multicolumn{4}{|l|}{$\mathrm{CEA}^{\mathrm{a}}$ diameter $(\mathrm{cm})$} \\
\hline-3.9 & 15 & 4 & 19 \\
\hline $4.0-4.9$ & 12 & 5 & 17 \\
\hline $5.0-5.9$ & 11 & 14 & 25 \\
\hline $6.0^{-}$ & 12 & 18 & 30 \\
\hline Mean $(\mathrm{cm})$ & 4.6 & 5.4 & 5.0 \\
\hline \multicolumn{4}{|l|}{ CEA patterns } \\
\hline Homogeneous & 9 & 4 & 13 \\
\hline Heterogeneous & 16 & 12 & 28 \\
\hline Ring-like & 25 & 25 & 50 \\
\hline \multicolumn{4}{|l|}{ Surrounding $\mathrm{LDA}^{\mathrm{b}}$} \\
\hline Grade 0 & 19 & 12 & 31 \\
\hline Grade 1 & 11 & 12 & 23 \\
\hline Grade 3 & 13 & 12 & 25 \\
\hline Grade 4 & 7 & 5 & 12 \\
\hline Total & 50 & 41 & 91 \\
\hline
\end{tabular}

${ }^{a} \mathrm{CEA}$, contrast enhanced area;

${ }^{\mathrm{b}} \mathrm{LDA}$, low density area, see text for grading. 
irradiation (IORT) followed by 40 Gy of uneven fractionated irradiation combined with the chemotherapy using ACNU $(1 \mathrm{mg} / \mathrm{kg})$. Twenty-eight patients underwent curative resection (more than $95 \%$ removal), 28 partial resections and 35 biopsies.

According to the CT scan which was taken before treatment, the tumor location, the diameter of contrast enhanced area (CEA), the patterns of CEA and the relative size of low density area (LDA) surrounding the CEA were examined (Table 1). The degree of the LDA size was defined as follows: grade 0 had no LDA, grade 1 had less than double the size of the CEA, grade 2 had double the size of the CEA and grade 3 had more than double the size of the CEA. There was no specific CT patterns which distinguished anaplastic astrocytoma and glioblastoma.

The Kaplan-Meier method was used for the calculation of the survival rates from the beginning of irradiation. A statistical comparison of the survival rates was performed with the Log-rank test. A multi-variate analysis for the survival time using Cox's proportional hazard model was carried out to evaluate the prognostic factors.

\section{RESULTS}

The survival rates by the treatment method are shown in Table 2. Although the LDRT group and the IORT group had worse survival than the conventionally fractionated group and the uneven fractionated group, the difference was not significant. There was also no significant difference among the survival rates of the subgroups by the curability of the surgical resection. Anaplastic astrocytoma had a significantly better prognosis than the glioblastoma $(p<0.01)$. Patients with a right hemisphere tumors showed better survival than the other side tumors, but the difference was not significant. The frontal and the parietal tumors exhibited better prognosis. However, the difference was not significant (Table 3). Based on the CT scan which was taken before treatment, the survival rate of patients with the CEA diameter of under $4 \mathrm{~cm}$ was significantly higher than that

TABLE 2. Survival rates by treatment methods

\begin{tabular}{lcccc}
\hline & Number of patients & \multicolumn{3}{c}{ Survival rate (\%) } \\
\cline { 3 - 5 } & & $12 \mathrm{~m}$ & $36 \mathrm{~m}$ & $60 \mathrm{~m}$ \\
\hline Radiation method & 44 & 47.2 & 18.9 & 13.8 \\
$\quad$ Conventional & 31 & 61.3 & 26.1 & 13.1 \\
Uneven fraction & 8 & 25.0 & 12.5 & 0 \\
LDRT $^{\mathrm{a}}$ & 8 & 87.5 & 0 & 0 \\
IORT $^{\mathrm{b}}$ & & & & \\
Surgical treatment & 28 & 60.7 & 25.0 & 17.9 \\
$\quad$ Curative & 28 & 57.1 & 12.9 & 12.9 \\
$\quad$ Non-curative & 35 & 45.7 & 18.7 & 0 \\
$\quad$ Biopsy & & &
\end{tabular}

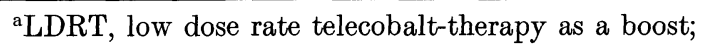

${ }^{\mathrm{b}} \mathrm{IORT}$, intraoperative radiation therapy. 
TABLE 3. Survival rates by histopathologic diagnosis and tumor location

\begin{tabular}{|c|c|c|c|c|c|}
\hline & \multirow{2}{*}{ Number of patients } & \multicolumn{4}{|c|}{ Survival rate $(\%)$} \\
\hline & & $12 \mathrm{~m}$ & $36 \mathrm{~m}$ & & $60 \mathrm{~m}$ \\
\hline \multicolumn{6}{|l|}{ Histology } \\
\hline Astrocytoma III & 50 & 63.7 & 31.4 & 18.4 & \multirow{2}{*}{$p<0.01$} \\
\hline Glioblastoma & 41 & 41.5 & 4.9 & 0 & \\
\hline \multicolumn{6}{|l|}{ Tumor location } \\
\hline Right side & 44 & 61.0 & 22.0 & 15.7 & \\
\hline Left side & 36 & 50.0 & 15.6 & 6.2 & \\
\hline Both side & 11 & 36.4 & 18.2 & 9.1 & \\
\hline \multicolumn{6}{|l|}{ Tumor location } \\
\hline Frontal & 30 & 62.7 & 19.4 & 11.6 & \\
\hline Temporal & 29 & 44.8 & 18.4 & 9.2 & \\
\hline Parietal & 14 & 50.0 & 28.6 & 21.4 & \\
\hline Occipital & 11 & 72.7 & 18.2 & 0 & \\
\hline Others & 7 & 28.6 & 14.3 & 14.3 & \\
\hline
\end{tabular}

of the others $(p<0.05)$. The homogeneous CEA group had a significantly better survival than the ring-like CEA group $(p<0.05)$. The grade of the LDA surrounding the CEA had no great effect for the patients' survival (Table 4).

The variables of the curability of surgical treatment, the histopathologic

TABLE 4. Survival rates by $C T$ patterns

\begin{tabular}{|c|c|c|c|c|c|}
\hline & \multirow{2}{*}{ Number of patients } & \multicolumn{4}{|c|}{ Survival rate $(\%)$} \\
\hline & & $12 \mathrm{~m}$ & $36 \mathrm{~m}$ & & $60 \mathrm{~m}$ \\
\hline \multicolumn{6}{|c|}{ CEA diameter $(\mathrm{cm})$} \\
\hline-3.9 & 19 & 68.4 & 40.5 & 27.0 & \multirow{3}{*}{$p<0.02$} \\
\hline $4.0-5.9$ & 42 & 54.5 & 12.4 & 5.0 & \\
\hline $6.0-$ & 30 & 43.3 & 15.6 & 10.4 & \\
\hline \multicolumn{6}{|l|}{ CEA patterns } \\
\hline Homogeneous & 13 & 76.2 & 42.3 & 31.9 & \multirow{3}{*}{$p<0.05$} \\
\hline Heterogeneous & 28 & 53.6 & 27.6 & 13.8 & \\
\hline Ring-like & 50 & 48.0 & 10.0 & 5.0 & \\
\hline \multicolumn{6}{|l|}{ Surrounding LDA } \\
\hline Grade 0 & 31 & 47.7 & 26.5 & 21.2 & \\
\hline Grade 1 & 23 & 39.1 & 5.4 & 5.4 & \\
\hline Grade 2 & 25 & 64.0 & 16.0 & 8.0 & \\
\hline Grade 3 & 12 & 75.0 & 33.3 & 8.3 & \\
\hline
\end{tabular}


difference, the CEA diameter and the CEA patterns were selected by stepwise method of Cox's proportional hazard model, and the histopathologic difference, the CEA diameter and the CEA pattern were significantly important prognostic factors. As for the curability of surgical treatment, biopsy showed higher relative risk (Table 5).

The survival rates were recalculated by the combination of the above three

TABLE 5. Multi-variate analysis by Cox's model

\begin{tabular}{lcl}
\hline \multicolumn{1}{c}{ Variable } & Scoring & $\begin{array}{c}\text { Relative risk } \\
(95 \% \text { confidence limit })\end{array}$ \\
\hline Surgical treatment & 1 & 1 \\
$\quad$ Curative & 2 & $1.23(0.94-1.62)$ \\
Non-curative & 3 & $1.52(1.16-2.00)$ \\
Biopsy & & \\
Histology & 1 & 1 \\
$\quad$ Anaplastic & & $1.99(1.25-2.00)$ \\
$\quad$ astrocytoma & 2 & \\
Glioblastoma & & 1 \\
CEA diameter (cm) & -3.9 & $1.16(1.01-1.33)$ \\
& $4.0-5.9$ & $($ per $1 \mathrm{~cm} \mathrm{increase)}$ \\
& $6.0-$ & 1 \\
CEA patterns & & $1.42(1.04-1.94)$ \\
Homogeneous & 1 & $2.01(1.47-2.76)$ \\
Heterogeneous & 2 & \\
Ring-like & 3 &
\end{tabular}

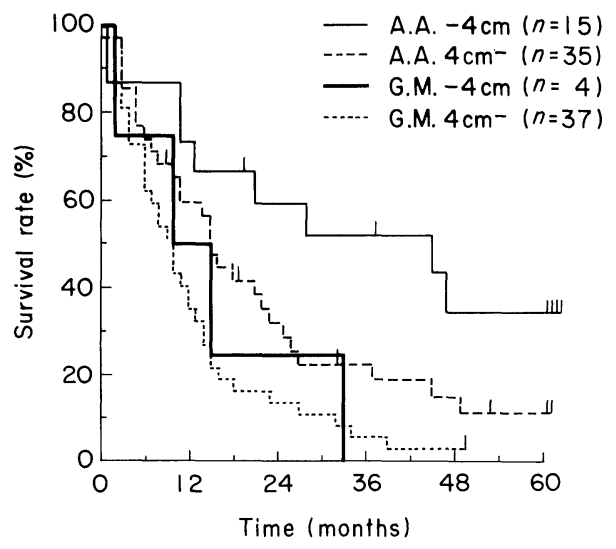

Fig. 1. Survival rates by the histopathologic diagnosis and the CEA diameter. A.A.,anaplastic astrocytoma; G.M., glioblastoma multiforme. 
factors. In anaplastic astrocytoma, tumors with a CEA diameter of under $4 \mathrm{~cm}$ had better prognosis than with a CEA diameter of more than $4 \mathrm{~cm}$, while in glioblastoma, the patients' prognosis was poor irrespective of the CEA diameter (Fig. 1). A homogeneous CEA group and a heterogeneous CEA group of anaplastic astrocytoma exhibited a better prognosis than the ring-like CEA group, but the difference was not significant (Fig. 2). On the other hand, a homogeneous CEA group of glioblastoma displayed a slightly better survival rate than the heterogeneous CEA group and the ring-like CEA group (Fig. 3). From the CEA diameter and the CEA patterns, tumors with under $4 \mathrm{~cm} \mathrm{CEA} \mathrm{in} \mathrm{diameter} \mathrm{showed} \mathrm{relative-}$ ly higher survival rates even in any CEA features (Fig. 4). Of patients with more than a $4 \mathrm{~cm}$ CEA tumor, only the homogeneous CEA group illustrated a better survival than the other pattern groups (Fig. 5). In other words, the prognosis of patients with a heterogeneous CEA and a ring-like CEA of more than $4 \mathrm{~cm}$ in diameter are worse than the other patients, when they are diagnosed as malignant

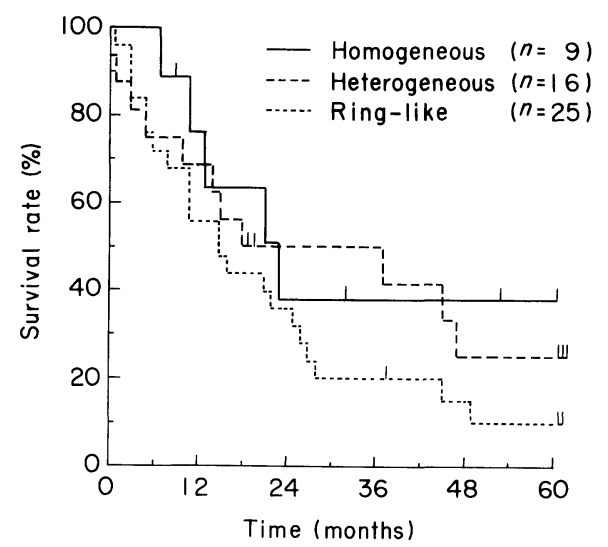

Fig. 2. Survial rates by the CEA paterns of the analastic astrocytoma cases.

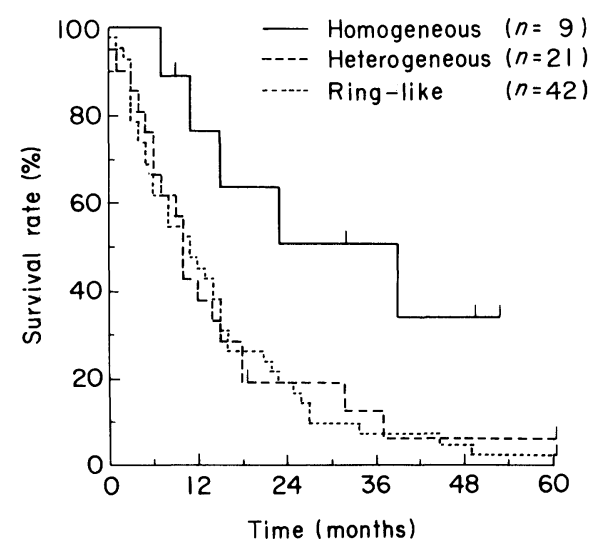

Fig. 3. Survival rates by the CEA patterns of the glioblastoma cases. 


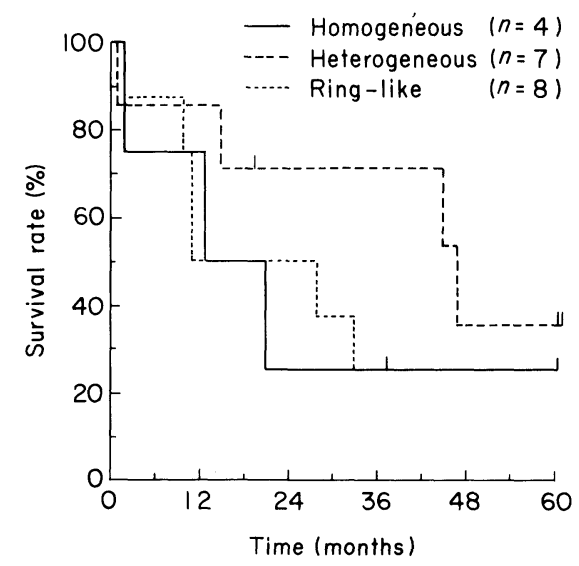

Fig. 4. Survival rates by the CEA patterns of patients with a CEA diameter of under $4 \mathrm{~cm}$.

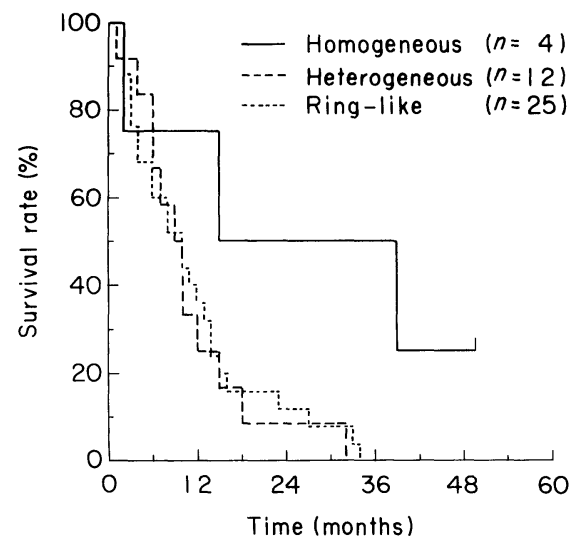

Fig. 5. Survival rates by the CEA patterns of patients with a CEA diameter of more than $4 \mathrm{~cm}$.

gliomas through clinical course.

\section{Discussion}

Various prognostic factors are proposed for malignant glioma. In general, patients of younger age (Nelson et al. 1986; Deutsch et al. 1989; Sandeman et al. 1990), with a good performance status (Nelson et al. 1986; Deutsch et al. 1989; Shapiro et al. 1989), without a coagulation necrosis in the tumor (Nelson et al. 1983) and treated with extensive surgery (Sandeman et al. 1990; Shibamoto et al. 1990), have a better prognosis. However, there are not many reports over the correlation between the CT scan and the prognosis (Norman et al. 1976; Levin et al. 1980; Andreou et al. 1983; Wood et al. 1988), and even if some papers are found, their conclusions are not universal. For example, Levin et al. (1980) 
reported that tumors with a smaller CEA and a peri-tumor LDA had better prognosis, but Andreou et al. (1983), Wood et al. (1988) and Shibamoto et al. (1990) concluded that the CEA diameter of the CT scan which was taken before treatment did not affect survival. Of all prognostic factors, the histopathologic findings are probably most closely connected with the prognosis. However, specimens are not taken from all tumors and do not express an integral feature of the tumors (Tchang et al. 1977). In some patients we have to start radiation therapy without any histopathological proof. We targeted the aim of this paper to investigate the correlation between the $\mathrm{CT}$ scan which was taken prior to treatment and the survival rate.

Although many treatment methods have been attempted for malignant glioma (Catterall et al. 1980; Nelson et al. 1986; Keim et al. 1987; Deutsch et al. 1989; Shapiro et al. 1989; Goodman et al. 1990; Brady et al. 1992), there was no improvement in the prognosis. We also tried different radiation methods, but there was no significant effect for survival. The curability of tumor resection did not affect the prognosis, either. The histopathologic diagnosis, the CEA diameter and the CEA pattern were important prognostic factors. A CEA diameter of 4 $\mathrm{cm}$ in pretreatment CT scan seems critical for the patients' survival. Further, by means of multi-variate analysis, the histopathologic diagnosis, the CEA diameter and the CEA patterns were the most important prognostic factors. We combined these three factors to examine stronger indicators for the patients' survival. When some tumors are histopathologically diagnosed as glioblastoma, there are no favorable prognostic factors. If some tumors are diagnosed as anaplastic astrocytoma, the patients with a CEA diameter of less than $4 \mathrm{~cm}$ and absence of ring-like enhancement have a better prognosis. Suppose some tumors have no histopathologic diagnosis and the clinical course suggests them as malignant, the tumors with a heterogeneous CEA or a ring-like CEA in the diameter of more than $4 \mathrm{~cm}$ have the worse prognosis and should be treated extensively by radiation therapy.

\section{References}

1) Andreou, J., George, A.E., Wise, A., deLeon, M., Kricheff, I.I., Ransohoff, J. \& Foo, S.H. (1983) CT prognostic criteria of survival after malignant glioma surgery. $\mathrm{Am}$. J. Neuro. Rad., 4, 488-490.

2) Brady, L.W., Miyamoto, C., Woo, D.V., Rackover, M., Emrich, J., Bender, H., Dadparvar, S., Steplewski, Z., Koprowski, H., Black, P., Lazzaro, B., Nair, S., McCormack, T., Nieves, J., Morabito, M. \& Eshleman, J. (1992) Malignant astrocytoma treated with iodine-125 labeled monoclonal antibody 425 against epidermal growth factor receptor: A phase II trial. Int. J. Radiat. Oncol. Biol. Phys., 22, 225-230.

3) Catterall, M., Bloom, H.J.G., Ash, D.V., Walsh, L., Richardson, A., Uttley, D., Growing, N.F.C., Levis, P. \& Chaucer, B. (1980) Fast neutrons compared with megavoltage $\mathrm{x}$-rays in the treatment of patients with supratentorial glioblastoma: A controlled pilot study. Int. J. Radiat. Oncol. Biol. Phys., 6, 261-266. 
4) Deutsch, M., Green, S.B., Strike, T.A., Burger, P.C., Robertson, J.T., Selker, R.G., Shapiro, W.R., Mealey, J., Jr., Ransohoff, J., II, Paoletti, P., Smith, K.R., Jr., Odom, G.L., Hunt, W.E., Young, B., Alexander, E., Jr., Walker, M.D. \& Pistenmann, D.A. (1989) Results of a randomized trial comparing BCNU plus radiotherapy, streptozotocin plus radiotherapy, BCNU plus hyperfractionated radiotherapy, and BCNU following misonidazole plus radiotherapy in the postoperative treatment of malignant glioma. Int. J. Radiat. Oncol. Biol. Phys., 16, 1389-1396.

5) Goodman, G.B., Skarsgard, L.D., Thompson, G.B., Harrison, R., Lam, G.K.Y. \& Lugate, C. (1990) Pion therapy at TRIUMF. Treatment results for astrocytoma grade 3 and 4: A pilot study. Radiother. Oncol., 17, 21-28.

6) Keim, H., Potthoff, P.C., Schmidt, K., Shiebusch, M., Neiss, A. \& Trott, K.R. (1987) Survival and quality of life after continuous accelerated radiotherapy of glioblastomas. Radiother. Oncol., 9, 21-26.

7) Levin, V.A., Hoffman, W.F., Heilbron, D.C. \& Norman, D. (1980) Prognostic significance of the pretreatment CT scan on time to progression for patients with malignant gliomas. J. Neurosurg., 52, 642-647.

8) Nelson, D.F., Diener-West, M., Weinstein, A.S., Schoenfeld, D., Nelson, J.S., Sause, W.T., Chang, C.H., Goodman, R. \& Carabell, S. (1986) A randomized comparison of misonidazole sensitized radiotherapy plus BCNU and radiotherapy plus BCNU for treatment of malignant glioma after surgery: Final report of an RTOG study. Int. J. Radiat. Oncol. Biol. Phys., 12, 1793-1800.

9) Nelson, J.S., Tsukada, Y., Shoenfeld, D., Fulling, K., Lamarche, J. \& Peress, N. (1983) Necrosis as a prognostic criterion in malignant supratentorial astrocytic gliomas. Cancer, 52, 550-554.

10) Norman, D., Enzmann, D.R., Levin, V.A., Wilson, C.B. \& Newton, T.H. (1976) Computed tomography in the evaluation of malignant glioma before and after therapy. Radiology, 121, 85-88.

11) Sandeman, D.R., Sandeman, A.P., Buxton, P., Hughes, H.H., Chadwick, D.W., Williams, I.R., Baker, R.D., Foy, P.M. \& Shaw, M.D.M. (1990) The management of patients with an intrinsic supratentorial brain tumor. Br. J. Neurosurg., 4, 299-312.

12) Shapiro, W.R., Green, S.B., Burger, P.C., Mahaley, M.S., Selker, R.G., VanGilder, J.C., Robertson, J.T., Ransohoff, J., Mealey, J., Strike, T.A. \& Pistenmann, D.A. (1989) Randomized trial of three chemotherapy regimens in postoperative treatment of malignant glioma. J. Neurosurg., 71, 1-9.

13) Shibamoto, Y., Yamashita, J., Takahashi, M., Yamasaki, T., Kikuchi, H. \& Abe, M. (1990) Supratentorial malignant glioma: An analysis of radiation therapy in 178 cases. Radiother. Oncol., 18, 9-17.

14) Tchang, S., Scotti, G., Terbrugge, K., Melançon, D., Bélanger, G., Milner, C. \& Ethier, R. (1977) Computerized tomography as a possible aid to histological grading of supratentorial gliomas. J. Neurosurg., 46, 735-739.

15) Wood, J.R., Green, S.B. \& Shapiro, W.R. (1988) The prognostic importance of tumor size in malignant gliomas: A computed tomographic scan study by the brain cooperative group. J. Clin. Oncol., 6, 338-343.

16) Ziulch, K.J. (1979) Histological Typing of Tumours of the Central Nervous System. World Health Organization, Geneva. 